\title{
Unusual Anatomy of Maxillary Second Premolars
}

Fábio de Almeida-Gomes ${ }^{a, c}$

Bruno Carvalho de Sousa

Fabricio Dias de Souza ${ }^{2}$

Roberto Alves dos Santos ${ }^{b}$

Cláudio Maniglia-Ferreirac

\section{ABSTRACT}

In this study, endodontic treatments of maxillary second premolars with unusual anatomical configuration were presented. Maxillary second premolars usually have one root with one or two root canals. The occurrence of variations in anatomical configuration is also common; therefore, it must be taken into account in clinical and radiographic evaluation during the endodontic treatment. These teeth may also require special shaping and filling techniques. This article reports and discusses the treatment recommendations for unusual occurrences of anatomical configurations in four different maxillary second premolars. (Eur J Dent 2009;3:145-149)

Key words: Dental anatomy; Root canal; Maxillary second premolar.

\section{INTRODUCTION}

A clear understanding of the root canal anatomy of the human dentition is a prerequisite for conventional endodontic procedures. The anatomical complexities of root canal anatomy have been highlighted in the literature and the need for the clinician to understand probable aberrations was emphasized. ${ }^{1}$

Consistent, high levels of success in endodontic treatment require an understanding of root canal

- a PhD Student, Department of Endodontics, University of Pernambuco, Pernambuco, Brazil. b Adjunct Professor, Department of Endodontics, University of Pernambuco, Pernambuco, Brazil. Assistant Professor, Department of Endodontics, University of Fortaleza, CE, Brazil.

- Corresponding author: Fábio de Almeida-Gomes Rua Arquiteto Reginaldo Rangel 155, ap.1403, Cocó, Fortaleza, Ceará, Brazil, CEP:60191-250. E-mail: fabiogomesceldyahoo.com.br anatomy and morphology and that the entire root canal system must be debrided, disinfected and filled. Thus, it is necessary for the clinician to have knowledge of not only understand dental anatomy but its variations. ${ }^{2}$

Inferior technical quality of root fillings is considered to be the main cause of clinical failure. Incomplete obturation of the root canal leaves residual space for microbial colonization and proliferation and may also imply that cleaning was incomplete. ${ }^{3,4}$ Therefore, the correct location, clean, shape and obturation of all canals are indispensable procedures. Similarly, Vertuci, ${ }^{5} \mathrm{De}$ Grood and Cunninghan ${ }^{6}$ and Maniglia-Ferreira et $\mathrm{al}^{7}$ reported that a considerable number of failures could be assigned to anatomical variations, such as the presence of canals not usually found.

Maxillary second premolars usually have 
one root with one or two root canals. Vertucci ${ }^{5}$ reported the occurrence of one canal at the apex in them at $75 \%$, and two canals at apex at $24 \%$. In the same study, Vertucci ${ }^{5}$ found maxillary second premolars with three canals at apex to be only $1 \%$. Studies on maxillary premolars show a low incidence of three root canals. ${ }^{8-10}$

The purpose of this study was to report endodontic treatments of maxillary second premolars with different anatomical configurations.

\section{CASE REPORT 1}

A 32 yr-old male patient with non-contributory medical history was referred to our office complaining of discomfort associated with left maxillary. Clinical examination revealed a temporary restoration in the left maxillary second premolar. The tooth was very sensitive to percussion. There was no tenderness to palpation. The buccal sulcus was nonresponsive to Endo Ice (Higenic Corp., Akron, Ohio). After the administration of the local anesthesic $12 \%$ Lignocaine with 1:100.000 epinephrine), the tooth was isolated and the coronal access was prepared. On entry into the pulp chamber, three different canal orifices (two buccals and one palatal) were found, which the initial radiographic exam did not suggest (Figure 1A). The access cavity was enlarged to a triangular outline. The canals were cleansed and the length of each root-canal was established using an electronic apex locator Root ZX (J. Morita, Kyoto, Japan). The root canals were prepared in a crown-down method using gatesglidden drills and hand files (Flexofile, Dentsply,
Maillefer). Sodium hypochlorite (2.5\%) and EDTA $(17 \%)$ solutions were used as irrigants. After cleaning and shaping, the canals were dried and filled by Tagger's technique using gutta-percha points and root canal sealer (Endofill, Denstply, Petropolis, Rio de Janeiro, Brazil). Treatment was executed in a single visit. After the filling, the final radiograph showed the three root canals with distinct foramens (Figure 1B). A sterilized cotton pellet was placed in the pulp chamber, the access cavity sealed with Cavit (ESPE, Seefeld, Germanyl and the patient dismissed.

\section{CASE REPORT 2}

A $30 \mathrm{yr}$-old female patient with noncontributory medical history was referred by her general dental practitioner for endodontic treatment of her maxillary right second premolar. The pulp of tooth had become necroses. This relieved the initial symptoms, but the tooth was still symptomatic to percussion. No swelling or fistula was present and the pulpal tissue was necrotic. Clinical examination revealed a mesial caries in the maxillary second premolar. The initial radiographic exam showed one canal leaving the pulp chamber and dividing short of the apex into two separated and distinct canals with separate apical foramina (Figure 2A).

The tooth was anaesthetized, isolated with rubber dam and the temporary restoration was removed. In order to verify the working lengths, an electronic apex locator was used (Root ZX, J. Morita Inc.). The root canal was prepared in a crown-down method with Gates-Glidden drills (Dentsply-Maillefer, Ballaigues, Switzerland)

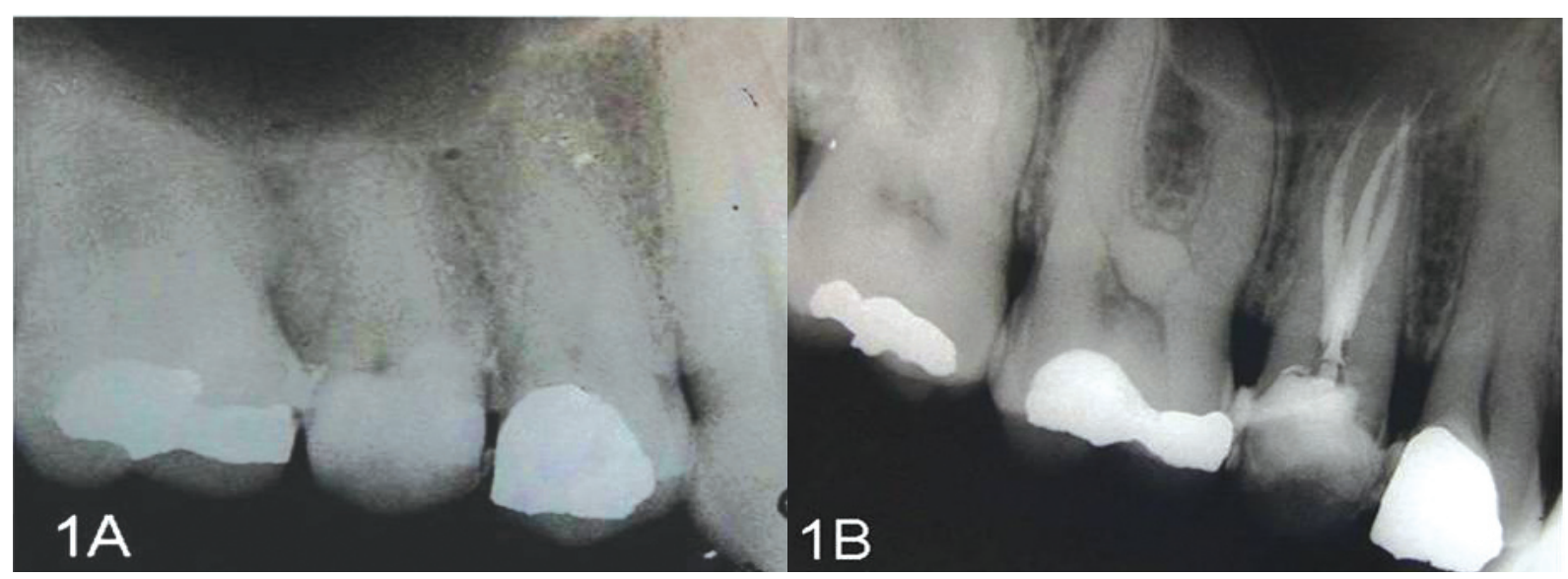

Figure 1. Case 1: $(A)$ pretreatment radiograph; $(B)$ root-canal filled showing three root canals with distinct foramens. 
numbers 2-4 at the cervical and middle-thirds of the root canals. The manual instrument size 15 was used to apical patency. Sodium hypochlorite $(2.5 \%)$ and EDTA $(17 \%)$ solutions were used as irrigant. The canals were filled by Tagger's technique using gutta-percha points and root canal sealer (Endofill, Denstply, Petropolis, Rio de Janeiro, Brazil). Treatment was executed in a single visit. After the filling, the final radiographic exam showed one canal in the pulp chamber dividing short of apex into two separated and distinct canals with separate apical foramens (Figure 2B).

\section{CASE REPORT 3}

A 45-yr-old male patient with a noncontributory medical history was referred to our office complaining of severe discomfort associated with his maxillary right second molar. Clinical examination revealed the presence of a resin restoration. The patient reported discomfort associated with cold, hypersensitiveness and lingering pain. The pulpal diagnosis was an irreversible pulpitis.

Radiographically, the root canal morphology displayed a normal anatomical configuration (Figure 3A). After the administration of the local anesthesic solution (2\% Lignocaine with 1:100.000 epinephrine), the tooth was isolated with a rubber dam and the coronal access was prepared. Two canals were localized however they were finishing in only one foramen (Figure

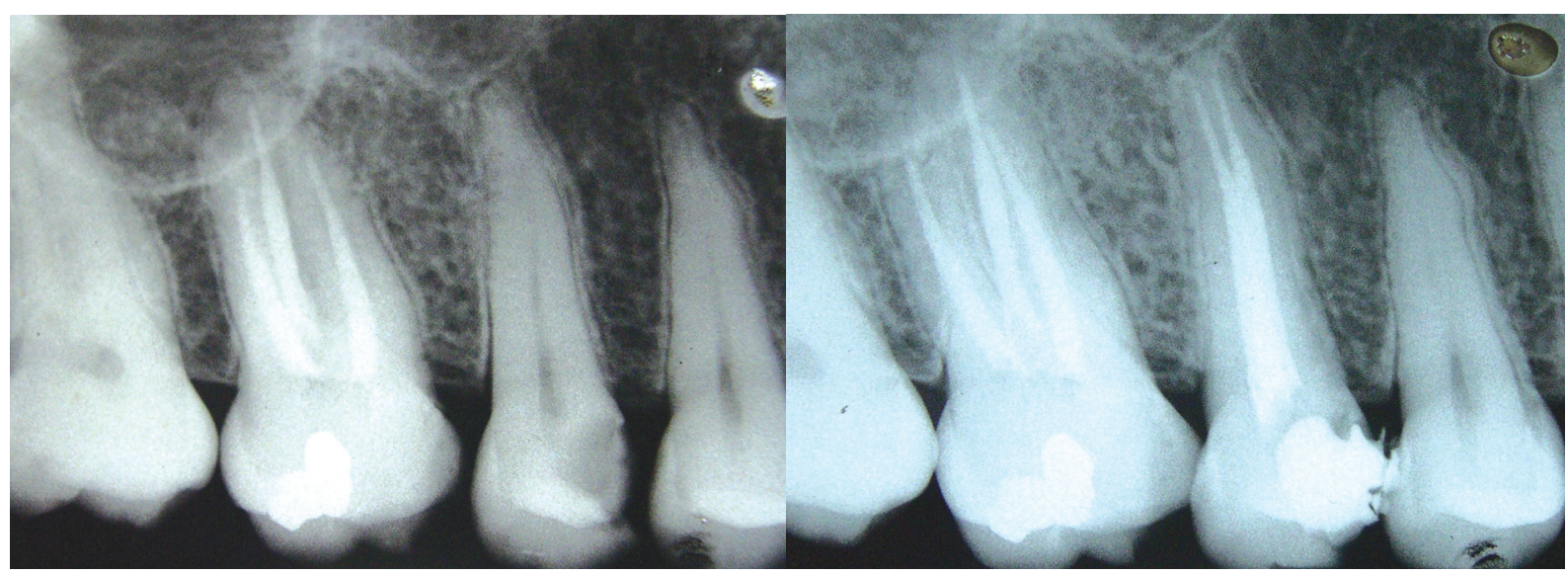

Figure 2. Case 2: (A) pretreatment radiograph; (B) root-canal filled showing one canal in the pulp chamber dividing short of apex into two separated and distinct canals with separate apical foramens.

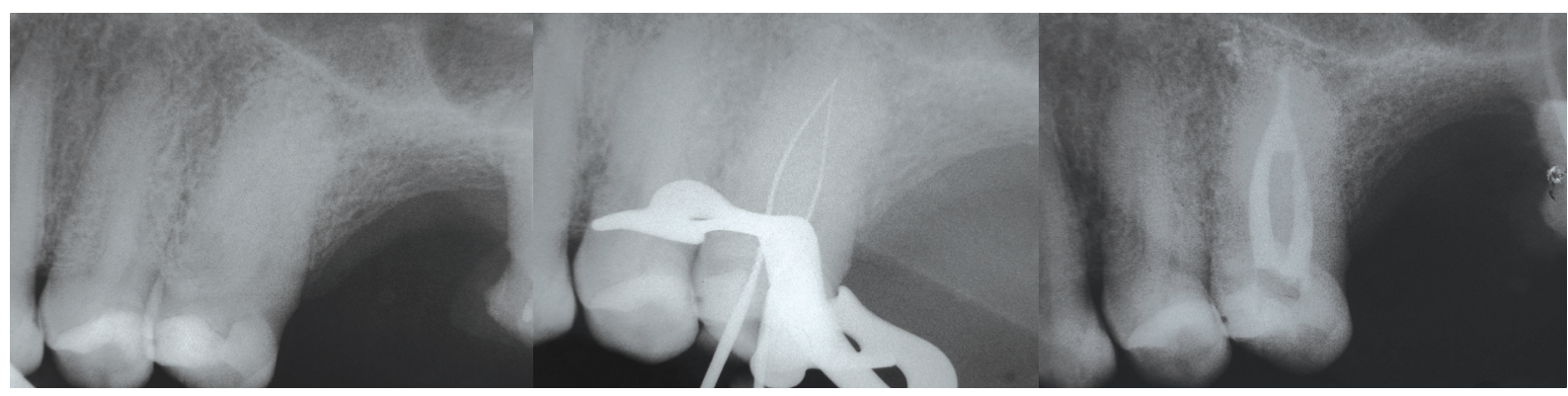

Figure 3. Case 3: (A) pretreatment radiograph; (B) position of endodontics instruments in the two root-canals; (C) Root-canal filled showing two canals with isthmus area filled and finishing in only one lateral foramen.

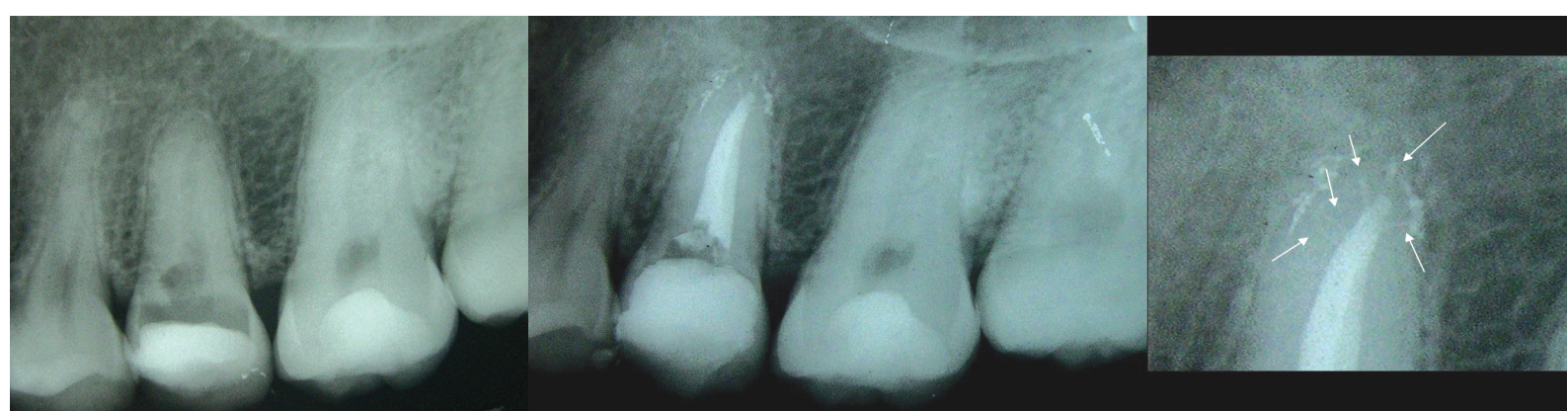

Figure 4. Case 4: (A) pretreatment radiograph; (B) Root-canal filled showing one canal with a lot of foraminas around the apical area. 
3B). The canals were cleaned and the length of root-canal was established using electronic apex locator (Root ZX; J. Morita Inc.). The root canals were prepared in a crown-down method with Gates-Glidden drills (Dentsply-Maillefer, Ballaigues, Switzerland) numbers 2-4 at the cervical and middle-thirds of the root canals. The manual instrument size 10 was used to apical patency. Sodium hypochlorite $(2.5 \%)$ and EDTA $(17 \%)$ solutions were used as irrigant. The canals were filled by Tagger's technique and root canal sealer (Endofilll, Dentsply, Petropolis, Rio de Janeiro, Brasil). Treatment was executed in a single visit. After the filling, the final radiographic exam showed two canals with isthmus area filled and finishing in only one lateral foramen (Figure 3C).

\section{CASE REPORT 4}

A 54 yr-old female patient with noncontributory medical history was referred to our office complaining of few discomfort associated with left maxillary. Clinical examination revealed temporary restoration in the left maxillary second premolar. The tooth was very sensitive to percussion and was nonresponsive to Endo Ice (Higienic, Corp., Akron, Ohio).

A pre-treatment radiograph was taken (Figure $4 \mathrm{~A}$ ), a conventional coronal access was performed and the tooth was isolated with a rubber dam. Only one canal was localized. The canal was cleaned and the length of root-canal was established using electronic apex locator (Root ZX; J. Morita Inc.). Sodium hypochlorite (4.5\%) and EDTA (17\%) solutions were used as endodontic irrigant. Cleaning and shaping was initiated using the crown-down technique with Gates-Glidden drills (Dentsply-Maillefer, Ballaigues, Switzerland) numbers 2-5 at the cervical and middle-thirds of the root canals. The manual instrument size 15 was used to apical patency.

The canal was dried and filled by a vertically condensed gutta-percha technique, with a Touch an Heat electric heat source (Kerr UK, Petreborough, UKJ and Tagger's technique was used for the backfilling using gutta-percha points and root canal sealer (AH-Plus, Denstply, Petropolis, Rio de Janeiro, Brazil). Treatment was executed in a single visit. After the filling, the final radiographic exam showed a one canal with a lot of foraminas around the apical area (Figure $4 \mathrm{~B})$.

\section{DISCUSSION}

According to Leonardo, ${ }^{11}$ an inability to detect, locate, negotiate and instrument all root canals may lead to endodontic failure. Textbooks describe in detail the "typical morphology" of any tooth, but one should always note published case reports presenting variations and/or irregularities of the pulp space.

Accurate preoperative radiographs, straight and angled, using a parallel technique are essentials in providing clues to the number of roots that exist. ${ }^{12}$

Endodontic success in teeth with the number of canals above normal requires a correct diagnosis and careful radiographic inspection. Morphological variations in pulpal anatomy must be always considered before beginning treatment.

This study presented the treatment of four cases with different anatomical configurations in second maxillary premolars. Determining the developmental origin of this anatomical anomaly appeared to have clinical significance.

\section{CONCLUSIONS}

Knowledge of dental anatomy is fundamental for good endodontic practice. Although the frequency of maxillary second premolars with an abnormal anatomic configuration is common, each case should be investigated clinically and radiographically to detect the anatomical anomaly.

\section{REFERENCES}

1. De Deus QD. Frequency, location and direction of tha lateral, secondary and accessory canals. J Endod 1975;1:361-366.

2. Baratto-Filho F, Fariniuk LF, Ferreira EL, Pecora JD, CruzFilho AM, Sousa-Neto MD. Clinical and macroscopic study of maxillary molars with two palatal roots. Int Endod $J$ 2002;35:796-801.

3. DeCleen M J H, Schuurs A H B, Wesselink P R, Wu M-K Periapical status and prevalence of endodontic treatment in an adult Dutch population. Int Endod J1993;26:112-119.

4. Ingle JI. Endodonticas. 3rd ed. Philadelphia, PA: Saunders; 1985.

5. Vertucci FJ. Root canal anatomy of the human permanent teeth. Oral Surg 1984;58:589-599. 
6. De Grood ME, Cunningham CJ. Mandibular molar with five canals: report of case. J Endod 1997;23:60-62.

7. Maniglia-Ferreira C, Almeida-Gomes F, Sousa BC, Lins CCSA, Santos RA. A case of unusual anatomy in second mandibular molar with four canals. Eur J Dent 2008;2:217219.

8. Atieh MA. Root and canal morphology of maxillary first premolars in a Saudi population. J Contemp Dent Pract 2008;9:46-53.

9. Ferreira CM, Moraes IG, Bernardineli N. Three-rooted maxillary second premolar. J Endod 2000;26:105-106.

10. Woodmansey KF. Endodontic treatment of a threerooted maxillary first premolar: a case report. Gen Dent 2006;54:420-424.

11. Leonardo MR. Aspectos anatômicos da cavidade pulpar: relações com o tratamento de canais radiculares. In: Leonardo MR, Leal JM. Eds. Endodontia: tratamento de canais radiculares. 3rd ed. São Paulo: Panamericana; 1998. p.191.

12. Silha RE. Paralleling long cone technique. Dental Rad Photo 1968;41:3-19. 